\title{
Tratamentos para superar dormência de sementes de Cassia fistula L.
}

\author{
Roberta Sales Guedes * \\ Edna Ursulino Alves \\ Sueli da Silva Santos-Moura \\ Edilson Guedes da Costa \\ Paulo Alexandre Fernandes Rodrigues de Melo \\ Universidade Federal de Santa Catarina \\ Rodovia Admar Gonzaga, 1346, Itacorubi, CEP 88034-000, Florianópolis - SC, Brasil \\ * Autor para correspondência \\ guedes.r.s@ufsc.br
}

Submetido em 24/10/2012

Aceito para publicação em 28/08/2013

\section{Resumo}

A espécie Cassia fistula L. (Fabaceae - Caesalpinioidea) propaga-se por sementes, e para promover a produção das mudas faz-se necessário superar a dormência natural das sementes que é causada pela impermeabilidade do tegumento à água. Assim, objetivou-se avaliar diferentes tratamentos pré-germinativos para superar a dormência de sementes de C. fistula. As sementes foram submetidas aos seguintes tratamentos: testemunha - sementes intactas ( $\left.\mathrm{T}_{1}\right)$; escarificação mecânica com lixa d'água no 80 na região lateral da semente $\left(\mathrm{T}_{2}\right)$; escarificação mecânica com lixa d'água $\mathrm{n}^{\circ} 80$, seguida de embebição em água à temperatura ambiente por 12 e $24 \mathrm{~h}\left(\mathrm{~T}_{3}\right.$ e $\mathrm{T}_{4}$, respectivamente); imersão em ácido sulfúrico por 1, 5, 10, 15 e 20 min $\left(\mathrm{T}_{5}, \mathrm{~T}_{6}, \mathrm{~T}_{7}, \mathrm{~T}_{8}, \mathrm{~T}_{9}\right.$, respectivamente) e imersão em água na temperatura de $100^{\circ} \mathrm{C}$ até esfriamento $\left(\mathrm{T}_{10}\right)$. As características avaliadas foram: porcentagem de emergência, primeira contagem de emergência, índice de velocidade de emergência, comprimento e massa seca de plântulas. Os resultados dos tratamentos que envolveram a imersão em água na temperatura de $100^{\circ} \mathrm{C}$ não superaram a dormência de sementes de C. fistula. A maior porcentagem de emergência das plântulas de $C$. fistula foi observada para sementes escarificadas com lixa d'água $n^{\circ} 80$ na região lateral da semente.

Palavras-chave: Análise de sementes; Chuva de ouro; Escarificação; Sementes florestais

\section{Abstract}

Treatments to break the dormancy of Cassia fistula L. seeds. Cassia fistula L. (Fabaceae Caesalpinioidea) is a forest species that is propagated by seeds. To promote the production of seedlings of $C$. fistula it is necessary to break the natural dormancy of its seeds, which is caused by the seed tegument that is impermeable to water. The goal of this study was to establish a pre-germination treatment for germinating C. fistula seeds. The seeds were subjected to the following treatments: control - intact seeds $\left(\mathrm{T}_{1}\right)$; mechanical scarification with sandpaper $n^{\circ} 80$ on the side of the seed $\left(\mathrm{T}_{2}\right)$; mechanical scarification with sandpaper $\mathrm{n}^{\circ} \mathbf{8 0}$, followed by immersion in water, at room temperature, for 12 and 24 hours $\left(\mathrm{T}_{3}\right.$ and $\mathrm{T}_{4}$, respectively); immersion 
in sulfuric acid for 1, 5, 10,15, and $20 \mathrm{~min}\left(\mathrm{~T}_{5}, \mathrm{~T}_{6}, \mathrm{~T}_{7}, \mathrm{~T}_{8}\right.$ and $\mathrm{T}_{9}$, respectively); and immersion in water at $100^{\circ} \mathrm{C}$ until cool $\left(\mathrm{T}_{10}\right)$. We evaluated the percentage of emergence, first count emergence, emergence speed index, and the length and dry mass of the seedlings. The treatment that involved immersion in water at $100^{\circ} \mathrm{C}$ did not break the dormancy of the seeds. The highest percentage of emergence was for the treatment that scarified the side of the seeds with sandpaper $\mathrm{n}^{\circ} 80$.

Key words: Chuva de ouro; Forest seeds; Scarification; Seed analysis

\section{Introdução}

A espécie Cassia fistula L. é uma espécie florestal exótica conhecida comumente como chuva-de-ouro, cássia-imperial ou canafístula verdadeira, pertencente à família Fabaceae - Caesalpinioidea. É originária da Ásia e foi introduzida no Brasil há muitos anos, onde se encontra bastante disseminada nos estados litorâneos. É amplamente utilizada como árvore ornamental em ruas, praças e jardins e pode atingir até $15 \mathrm{~m}$ de altura e 4 a 6 $\mathrm{m}$ de diâmetro de copa (CORRÊA, 1984). A planta tem alto valor terapêutico devido aos efeitos cicatrizantes, antipiréticos, analgésicos e hipoglicemiantes, pode ser utilizada para tratamento de hipercolesterolemia, bem como laxante moderado para crianças e mulheres grávidas e também como tônico purgativo (LUXIMONRAMMA et al., 2002; LAGO et al., 2009). Atribui-se a atividade terapêutica aos derivados de antraquinonas, presentes nos tecidos vegetais, em especial nas sementes de onde podem ser isolados senosídeos e flavonoides (LAGO et al., 2009).

A C. fistula fornece madeira com cerne muito duro, de longa durabilidade, própria para marchetaria, obras de torno, construção naval, rodas, marcenaria de luxo, postes, esteios, mãos de pilão, cabos de ferramentas e de instrumentos agrícolas. Ainda, a polpa albuminosa que envolve as sementes é a parte mais importante da espécie, pois é utilizada como tempero, o qual é muito apreciado no preparo de certos tabacos orientais, e também em confeitarias e sorvetes. Os galhos novos são aceitos como forragem pelo gado em época de escassez (CORRÊA, 1984; SANTOS, 1987).

Muitas espécies florestais produzem sementes que, embora serem viáveis e possuir condições ambientais favoráveis para germinação, não germinam (SILVA et al., 2009). As sementes que não germinam podem permanecer viáveis por longos períodos no banco de sementes do solo com germinação lenta e irregular (MURDOCH; ELLIS, 2000). Este fenômeno, conhecido como dormência, corresponde ao estado em que sementes aptas a germinar suspendem temporariamente $o$ processo de desenvolvimento até que todas as condições externas ordinariamente consideradas necessárias ao seu crescimento sejam atendidas (POPINIGIS, 1977; BEWLEY; BLACK, 1994). Piña-Rodrigues e Aguiar (1993) evidenciam que a dormência é uma estratégia natural de sobrevivência da semente no solo após maturação e dispersão, com o objetivo de garantir a perpetuação da espécie. Neste caso, o conhecimento das causas é de significativa importância prática, visto que permite a aplicação de tratamentos apropriados para se obter melhor resultado na porcentagem de germinação das sementes (MELO et al., 1998).

Espécies que produzem sementes dormentes representam problema para os viveiristas, pois, o tegumento impermeável restringe a entrada de água e oxigênio, característica que promove resistência física ao crescimento do embrião e consequentemente retarda a germinação (MOUSSA et al., 1998). Os mesmos autores afirmam que a dormência é prejudicial à produção de mudas em virtude do longo tempo para que ocorra germinação, favorece também o ataque de fungos e acarreta grandes perdas.

O papel da tecnologia de sementes é adaptar ou criar métodos tecnológicos adequados em determinada espécie melhoria no padrão de qualidade das sementes, especialmente quando se trata de atividade de produção de mudas com objetivo de obtenção de estande uniforme.

Para promover a produção das mudas da espécie Cassia fistula faz-se necessário superar a dormência natural das sementes que é causada pela impermeabilidade do tegumento à água. A impermeabilidade do tegumento pode ser superada por meio da escarificação, a qual 
consiste na ruptura ou no enfraquecimento do tegumento. Ao ser enfraquecido, o tegumento permite a passagem de água e dando início ao processo germinativo (MAYER; POLJAKOFF-MAYBER, 1989). Entre os métodos utilizados com sucesso para a superação da dormência de espécies florestais destacam-se a escarificação mecânica, escarificação química com ácido sulfúrico e a imersão em água quente. A aplicação e a eficiência dos tratamentos para superação da dormência dependem da intensidade e do tipo da dormência, a qual é bastante variável entre espécies, e varia de acordo com as procedências e os anos de coleta (ALBUQUERQUE et al., 2007).

Foi obsevado que a escarificação mecânica do tegumento foi eficiente na superação da dormência das sementes de várias espécies com tegumento impermeável, como as sementes de Acacia mearnsii Willd. (ROVERSI et al., 2002), Peltophorum dubium (Spreng.) Taub. (PIROLI et al., 2005), Acacia caven (Mol.) Mol. (ESCOBAR et al., 2010), Apeiba tibourbou Aubl. (GUEDES et al., 2011).

Entre os mais diversos métodos aplicados para a superação da dormência tegumentar de sementes de espécies arbóreas brasileiras, destaca-se a escarificação química com ácido sulfúrico (SMIDERLE; SOUSA, 2003; LOPES et al., 2006). Esse método pode ser importante em espécies com sementes pequenas, já que, nesse caso, a escarificação mecânica do tegumento não é exequível (BRANCALION et al., 2011). Este método foi empregado com eficiência na superação da dormência de sementes Ormosia nitida Vog. (LOPES et al., 2006), Merremia aegyptia L. (PEREIRA et al., 2007),
Bowdichia virgilioides Kunth. (ALBUQUERQUE et al., 2007), Acacia mangium Willd. (RODRIGUES et al., 2008) e Adenanthera pavonina L. (RODRIGUES, 2009).

O uso da água quente para superar a dormência em sementes com impermeabilidade tegumentar é recomendado para algumas espécies florestais (FOWLER; BIANCHETTI, 2000), no entanto, a eficiência do tratamento depende da espécie, temperatura de água e do tempo de imersão das sementes (SCHMIDT, 2000).

Nas sementes de Cassia fistula evidencia-se dormência ligada à impermeabilidade do tegumento à água e por isso considerável número de sementes permanece sem germinar, principalmente em bancos de sementes ou em sementeiras destinadas à formação de mudas. Dessa forma, objetivou-se avaliar a eficácia da aplicação de diferentes tratamentos para superação da dormência das sementes de $C$. fistula.

\section{Material e Métodos}

Para condução da pesquisa, coletaram-se frutos de Cassia fistula de dez árvores matrizes, no município de Souza - PB, os quais foram levados ao Laboratório de Análise de Sementes para beneficiamento manual das sementes. No beneficiamento utilizou-se uma marreta para quebrar os frutos, tendo sempre o cuidado de não causar lesões nas sementes. Depois de beneficiadas as sementes foram submetidas aos tratamentos descritos na Tabela 1.

TABELA 1: Tratamentos pré-germinativos aplicados para superação da dormência de sementes de Cassia fistula L.

\begin{tabular}{c|l}
\hline \multicolumn{1}{c}{ Descrição dos tratamentos pré-germinativos } \\
\hline $\mathrm{T}_{1}$ & Testemunha - sementes intactas \\
$\mathrm{T}_{2}$ & Escarificação mecânica com lixa d'água $\mathrm{n}^{\circ}$ 80 na lateral da semente \\
$\mathrm{T}_{3}$ & Escarificação mecânica com lixa d'água $\mathrm{n}^{\circ}$ 80, seguida de embebição em água por $12 \mathrm{~h}$ \\
$\mathrm{~T}_{4}$ & Escarificação mecânica com lixa d'água $\mathrm{n}^{\circ}$ 80, seguida de embebição em água por $24 \mathrm{~h}$ \\
$\mathrm{~T}_{5}$ & Imersão em ácido sulfúrico por $1 \mathrm{~min}$ \\
$\mathrm{~T}_{6}$ & Imersão em ácido sulfúrico por $5 \mathrm{~min}$ \\
$\mathrm{~T}_{7}$ & Imersão em ácido sulfúrico por $10 \mathrm{~min}$ \\
$\mathrm{~T}_{8}$ & Imersão em ácido sulfúrico por $15 \mathrm{~min}$ \\
$\mathrm{~T}_{9}$ & Imersão em ácido sulfúrico por $20 \mathrm{~min}$ \\
$\mathrm{~T}_{10}$ & Imersão em água na temperatura de $100^{\circ} \mathrm{C}$ até esfriamento \\
\hline
\end{tabular}


A escarificação mecânica manual foi efetuada por meio da fricção da região lateral do tegumento das sementes com a superfície abrasiva da lixa d'água $n^{\circ} 80$, até se observar suave desgaste do tegumento e exposição dos cotilédones. As sementes imersas em ácido sulfúrico ( $98 \%$ de PA) foram constantemente revolvidas com bastão de vidro para uniformizar a ação corrosiva do produto. Decorridos os períodos pré-estabelecidos, as sementes foram lavadas em água corrente por $10 \mathrm{~min}$, para que os resíduos do ácido sulfúrico fossem totalmente retirados. Para avaliação do efeito dos tratamentos foram avaliadas as características descritas a seguir.

\section{Teste de emergência de plântulas}

Após a aplicação dos tratamentos pré-germinativos as sementes foram submetidas ao teste de emergência. Os tratamentos foram instalados com quatro repetições de 25 sementes em casa de crescimento com temperatura média de $30^{\circ} \mathrm{C}$ e $68 \%$ de umidade relativa. As sementes foram distribuídas em bandejas plásticas com dimensões de $0,40 \times 0,40 \times 0,11 \mathrm{~m}$, que continham areia lavada e esterilizada. Foram realizadas irrigações diárias para manutenção da umidade do substrato. Foram realizadas contagens de plântulas emersas diariamente, do $8^{\circ}$ ao $15^{\circ}$ dias após a implantação do experimento. Foram registrados o número de plântulas que emitiram o epicótilo, e os resultados foram expressos em porcentagem.

\section{Primeira contagem de emergência}

Foi conduzida conjuntamente com o teste de emergência, onde se registrou plântulas que emergiram ao oitavo dia após a semeadura, sendo os resultados expressos em porcentagem.

\section{Índice de velocidade de emergência}

O índice de velocidade de emergência (IVE) foi determinado mediante contagem diária do número de plântulas emersas durante 15 dias e o índice determinado de acordo com a fórmula proposta por Maguire (1962);

onde $I V E=\frac{E_{1}+E_{2}+\ldots+E_{n}}{N_{1}+N_{2}+\ldots+N_{n}}$, em que IVE $=$ índice velocidade de emergência; $\mathrm{E}_{1}, \mathrm{E}_{2}, \ldots \mathrm{E}_{\mathrm{n}}=$ número de plântulas normais germinadas a cada dia; $\mathrm{N}_{1}, \mathrm{~N}_{2}, \ldots \mathrm{N}_{\mathrm{n}}$ = número de dias decorridos da semeadura da primeira até a última contagem.

\section{Comprimento de plântulas}

No final do teste de emergência, as plântulas normais de cada repetição foram medidas (da raiz à parte aérea), com o auxílio de uma régua graduada em centímetros, e os resultados expressos em cm/plântula.

\section{Massa seca de plântulas}

As mesmas plântulas da avaliação anterior foram acondicionadas em sacos de papel Kraft e levados a estufa regulada a $65^{\circ} \mathrm{C}$ até obtenção de massa constante (48 h). Após o período de $48 \mathrm{~h}$, as sementes foram pesadas em balança analítica com precisão de $0,001 \mathrm{~g} \mathrm{e}$ os resultados expressos em g/plântula.

\section{Análise estatística e delineamento experimental}

Foram utilizadas 100 sementes por tratamento, divididas em quatro repetições de 25 sementes e utilizado para avaliação dos tratamentos o delineamento experimental inteiramente ao acaso. Os dados obtidos, não transformados, foram submetidos à análise de variância pelo teste $\mathrm{F}$ e as médias comparadas pelo teste de Scott-Knott, a 5\% de probabilidade.

\section{Resultados e Discussão}

A ausência de germinação de sementes que não foram submetidas a nenhum tratamento pré-germinativo confirma a ocorrência de dormência tegumentar nas sementes desta espécie (Figura 1). Assim, confirma-se a hipótese de que estas exigem algum tipo de tratamento para superar a dormência e permitir a produção de mudas com padrão de qualidade e estande uniforme.

Quanto aos tratamentos utilizados constatou-se que o tratamento $\mathrm{T}_{2}$ proporcionou o maior porcentual de emergência de plântulas de C. fistula (94\%), e 
FIGURA 1: Emergência de plântulas de Cassia fistula L. oriundas de sementes submetidas a tratamentos para superar a dormência. $\mathrm{T}_{1}$ - Testemunha - sementes intactas; $\mathrm{T}_{2}$ - Escarificação mecânica com lixa d'água no 80 na lateral da semente; $\mathrm{T}_{3}$ e $\mathrm{T}_{4}-$ Escarificação mecânica com lixa d'água no 80 , seguida de embebição em água por $12 \mathrm{~h}$ e $24 \mathrm{~h}$, respectivamente; $\mathrm{T}_{5}, \mathrm{~T}_{6}, \mathrm{~T}_{7}, \mathrm{~T}_{8}$ e $\mathrm{T}_{9}$ - Imersão em ácido sulfúrico por 1, 5, 1015 e $20 \mathrm{~min}$, respectivamente; $\mathrm{T}_{10}$ - Imersão em água na temperatura de $100^{\circ} \mathrm{C}$ até esfriamento.

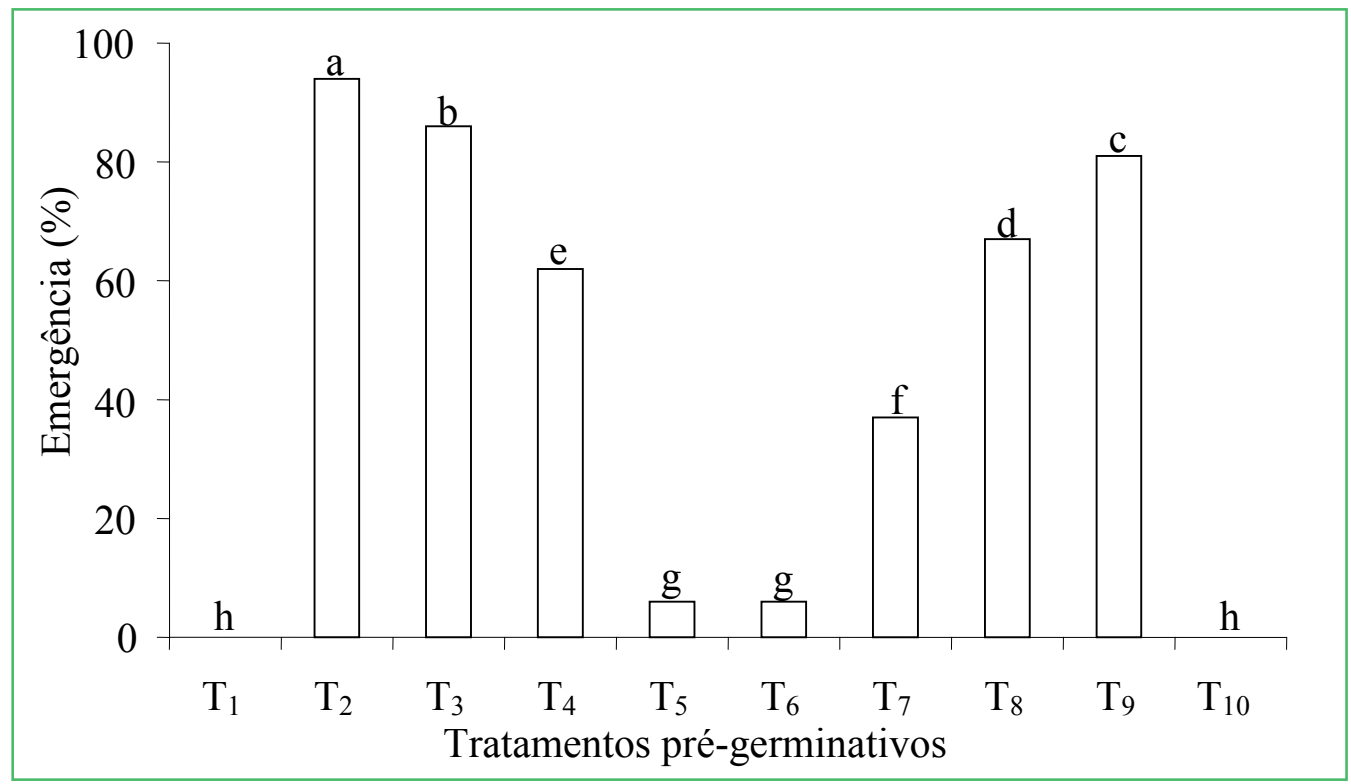

esse resultado indica que a dormência tegumentar foi superada satisfatoriamente quando as sementes foram submetidas à escarificação mecânica com lixa d'água nº 80 na região lateral da semente. Segundo Hartmann et al. (1997), para espécies que apresentam sementes com tegumento impermeável à água, um dos tratamentos mais comumente usados é a escarificação mecânica. Este método permite a formação de fissuras no tegumento, aumentando sua permeabilidade e favorecendo assim, a embebição e o início do processo de germinação. Os autores Mayer e Poljakoff-Mayber (1989) já haviam mencionado que no ambiente natural a dormência é superada por processos de escarificação, consistindo em qualquer tratamento que resulte na ruptura ou enfraquecimento do tegumento, o que possibilita a entrada de água e gases e, assim, dando início ao processo germinativo.

Resultados similares foram obtidos em sementes de Peltophorum dubium (Spreng.) Taub. em que a escarificação mecânica do lado oposto ao da emissão da radícula foi eficiente para superar a dormência (PIROLI et al., 2005). Para a superação da dormência das sementes de Adenanthera pavonina L. deve- se proporcionar abrasão com lixa no 80 durante 20 segundos (RODRIGUES, 2009). Para germinação das sementes de Apeiba tibourbou Aubl. recomendase a escarificação com lixa d'água $\mathrm{n}^{\circ} 80$ por 5 min (GUEDES et al., 2011). A escarificação por lixa na porção mediana da face lateral laranja-avermelhada das sementes de Ormosia arborea (Vell.) proporcionou os maiores porcentuais de germinação, pois os cortes no tegumento nesta região permitem difusão hídrica mais rápida e consequentemente emissão da raiz primaria (BASQUEIRA et al., 2011).

Os tratamentos de escarificação mecânica com lixa d'água no 80 seguidos da embebição em água por $12 \mathrm{~h}$ $\left(\mathrm{T}_{3}\right)$ proporcionou um porcentual de emergência de $86 \%$, porém quando as sementes de C. fistula foram expostas a períodos de embebição mais prolongados $\left(24 \mathrm{~h}-\mathrm{T}_{4}\right) \mathrm{se}$ revelaram como extremamente sensíveis à submersão, pois houve redução na velocidade e provocou redução da germinação para $62 \%$ (Figura 1 e 2). A rapidez com a qual ocorreu a embebição nas sementes submersas por $24 \mathrm{~h}$ pode ter causado injúrias nos tecidos das sementes, com reflexos na porcentagem de germinação. Castro et al. (2004) afirmam que quando colocadas para embeber 
FIGURA 2: Primeira contagem de emergência de plântulas de Cassia fistula L. oriundas de sementes submetidas a tratamentos para superar a dormência. $\mathrm{T}_{1}-$ Testemunha - sementes intactas; $\mathrm{T}_{2}-$ Escarificação mecânica com lixa d'água $\mathrm{n}^{\mathrm{o}} 80 \mathrm{na}$ lateral da semente; $\mathrm{T}_{3}$ e $\mathrm{T}_{4}$ - Escarificação mecânica com lixa d'água no 80 , seguida de embebição em água por $12 \mathrm{~h}$ e $24 \mathrm{~h}$, respectivamente; $\mathrm{T}_{5}, \mathrm{~T}_{6}, \mathrm{~T}_{7}$, $\mathrm{T}_{8}$ e $\mathrm{T}_{9}$ - Imersão em ácido sulfúrico por $1,5,10,15$ e $20 \mathrm{~min}$, respectivamente; $\mathrm{T}_{10}$ - Imersão em água na temperatura de $100^{\circ} \mathrm{C}$ até esfriamento.

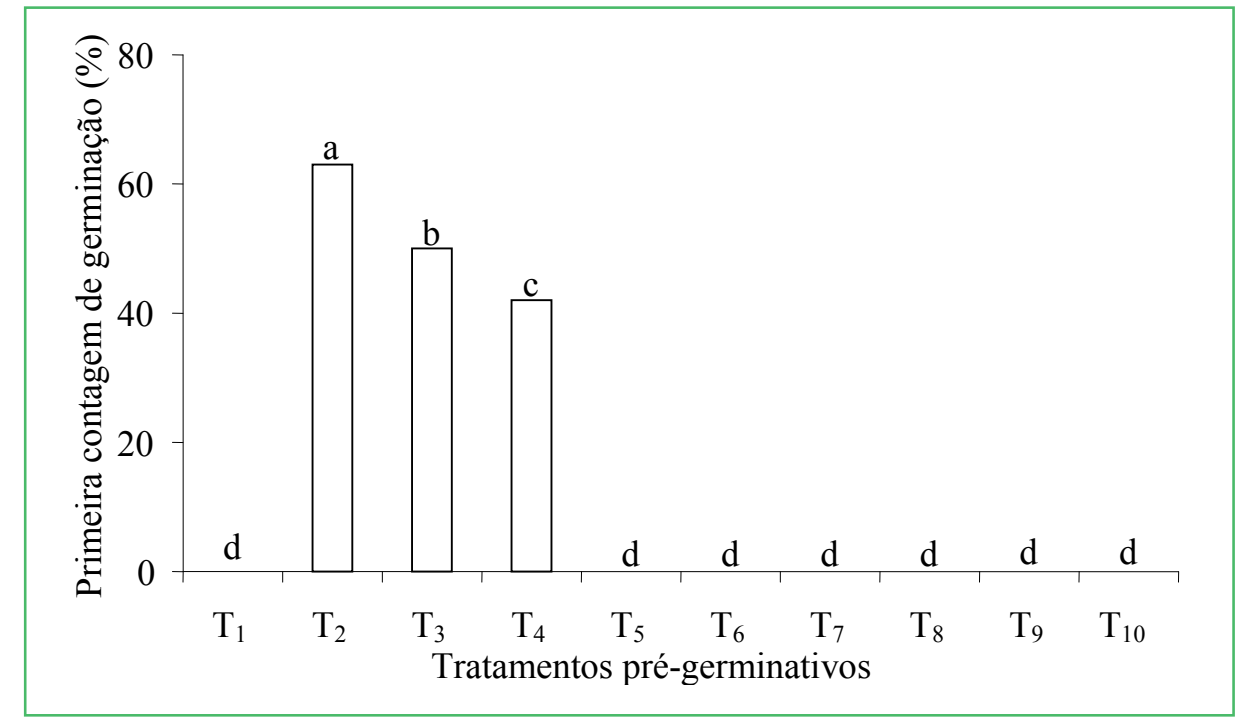

as sementes podem sofrer danos irreversíveis no sistema de membranas, e consequente lixiviação de conteúdos celulares que afeta negativamente a germinação. Esse resultado pode indicar ainda uma demanda crescente de oxigênio pelas sementes com o avanço da embebição e da ativação metabólica e, portanto, um possível déficit de oxigênio ocasionou a redução da capacidade germinativa, como foi verificado por Pinedo e Ferraz (2008) em sementes de Parkia pendula Penth. ex Walp.

Quando as sementes foram submetidas ao tratamento com água quente não houve emergência das plântulas e contabilizou-se o maior número de sementes mortas (Figura 1). Provavelmente, a alta temperatura empregada afetou a viabilidade e causou, a morte do embrião, detectado pela flacidez dos tecidos. Para sementes das espécies Acacia mangium Willd (SMIDERLE et al., 2005) o tratamento térmico superou a dormência tegumentar.

Entre os tratamentos em que se utilizou exclusivamente o ácido sulfúrico, a imersão por $20 \mathrm{~min}$ $\left(\mathrm{T}_{9}\right)$ foi a mais efetiva, promoveu $81 \%$ de emergência (Figura 1), pois responsável por ocasionar maior corrosão/porosidade do tegumento. A imersão por 1 e 5 $\min \left(\mathrm{T}_{5} \mathrm{e} \mathrm{T}_{6}\right)$ resultaram em $6 \%$ de emergência (ambos), provavelmente esses períodos foram insuficientes para promover a escarificação ou enfraquecimento completo do tegumento. Com o aumento do tempo de imersão para 10 e $15 \mathrm{~min}$, a porcentagem de emergência aumentou para $37 \%$ e $67 \%$ ( $\mathrm{T}_{7}$ e $\mathrm{T}_{8}$ respectivamente). Essas porcentagens podem ser consideradas elevadas para a espécie em questão, tendo em vista que sem nenhum tratamento para superar a dormência, as sementes não germinam.

Os resultados evidenciam que períodos maiores de exposição permitiram a entrada de água em quantidade adequada ao embrião. Além disso, pressupõe-se que o aumento do período de exposição das sementes de C. fistula ao ácido sulfúrico provocariam as rupturas necessárias no tegumento para a entrada de água e ampliar o porcentual de germinação. Pode-se notar ainda que não ocorreram danos às sementes com o aumento do tempo em imersão em ácido sulfúrico, haja vista, os crescentes e elevados percentuais obtidos. A imersão das sementes de Cassia grandis L. em ácido sulfúrico por 15, 30, 45 e $60 \mathrm{~min}$ promoveu porcentagens de germinação de, respectivamente, $76,6 \%, 78,3 \%, 75,0 \%$ e 90,0\% (SILVA et al., 2012). Santos (2008), testando a superação de dormência na mesma espécie com imersão em ácido sulfúrico por 5, 10 e 15 min, também obteve 
porcentagens elevadas, obtendo a melhor porcentagem de germinação para o tempo de 15 min de imersão, obtendo um valor de $91,1 \%$.

Os tratamentos das sementes de C. fistula com ácido sulfúrico demonstram-se efetivos na promoção da emergência e, consequentemente, na superação de dormência das sementes. No entanto, apesar da sua eficiência comprovada, o método de escarificação química com ácido sulfúrico não deve ser usado indiscriminadamente para sementes de quaisquer espécies. Portanto deve ser determinado para cada espécie o tempo de imersão das sementes em ácido sulfúrico, face à existência dos distintos níveis de dormência entre elas.

O ácido sulfúrico, além de ser eficaz para superar a dormência de sementes de C. fistula, também foi responsável pelo melhor comportamento em sementes de Ormosia nitida Vog. (10 min) (LOPES et al., 2006), Merremia aegyptia L. (10 min) (PEREIRA et al., 2007), Senna siamea (Lam.) H.S. Irwin e Barneby (15, 30 ou $45 \mathrm{~min}$ ) (DUTRA et al., 2007), Acacia mangium Willd.
(90 min) (RODRIGUES et al., 2008) e Senna alata L. (60 min) (BRAGA et al., 2010).

À semelhança da percentagem de emergência, os maiores porcentuais de plântulas normais na primeira contagem (63\%) também foram obtidos de sementes oriundas do tratamento $T_{2}$ (Figura 2). Nos tratamentos de escarificação mecânica com lixa d'água no 80 seguidos da embebição em água por 12 e $24 \mathrm{~h}\left(\mathrm{~T}_{3} \mathrm{e}\right.$ $\mathrm{T}_{4}$, respectivamente), constatou-se redução do vigor com o aumento dos períodos de embebição, quando comparados ao tratamento apenas com escarificação. Os tratamentos com ácido sulfúrico, independente do período de exposição, não promoveram germinação rápida e uniforme.

O maior índice de velocidade de emergência (IVE) $(3,78)$ das sementes de $C$. fistula foi obtido no tratamento $\mathrm{T}_{2}$ (escarificação mecânica com lixa d'água $\mathrm{n}^{0} 80$ na região lateral da semente), seguido dos tratamentos $\mathrm{T}_{3}$ e $\mathrm{T}_{4}$ (escarificação mecânica com lixa d'água $\mathrm{n}^{\circ} \mathrm{0}$ 80, seguida de embebição por 12 e 24 h) (Figura 3). Dentre os tratamentos que envolvem a imersão em ácido

FIGURA 3: Índice de velocidade de emergência de plântulas de Cassia fistula L. oriundas de sementes submetidas a tratamentos para superar a dormência. $T_{1}-$ Testemunha - sementes intactas; $T_{2}-$ Escarificação mecânica com lixa d'água no 80 na lateral da semente; $\mathrm{T}_{3}$ e $\mathrm{T}_{4}$ - Escarificação mecânica com lixa d'água no 80, seguida de embebição em água por $12 \mathrm{~h}$ e $24 \mathrm{~h}$, respectivamente; $\mathrm{T}_{5}, \mathrm{~T}_{6}, \mathrm{~T}_{7}, \mathrm{~T}_{8}$ e $\mathrm{T}_{9}-$ Imersão em ácido sulfúrico por 1, 5, 1015 e 20 min, respectivamente; $\mathrm{T}_{10}-$ Imersão em água na temperatura de $100^{\circ} \mathrm{C}$ até esfriamento.

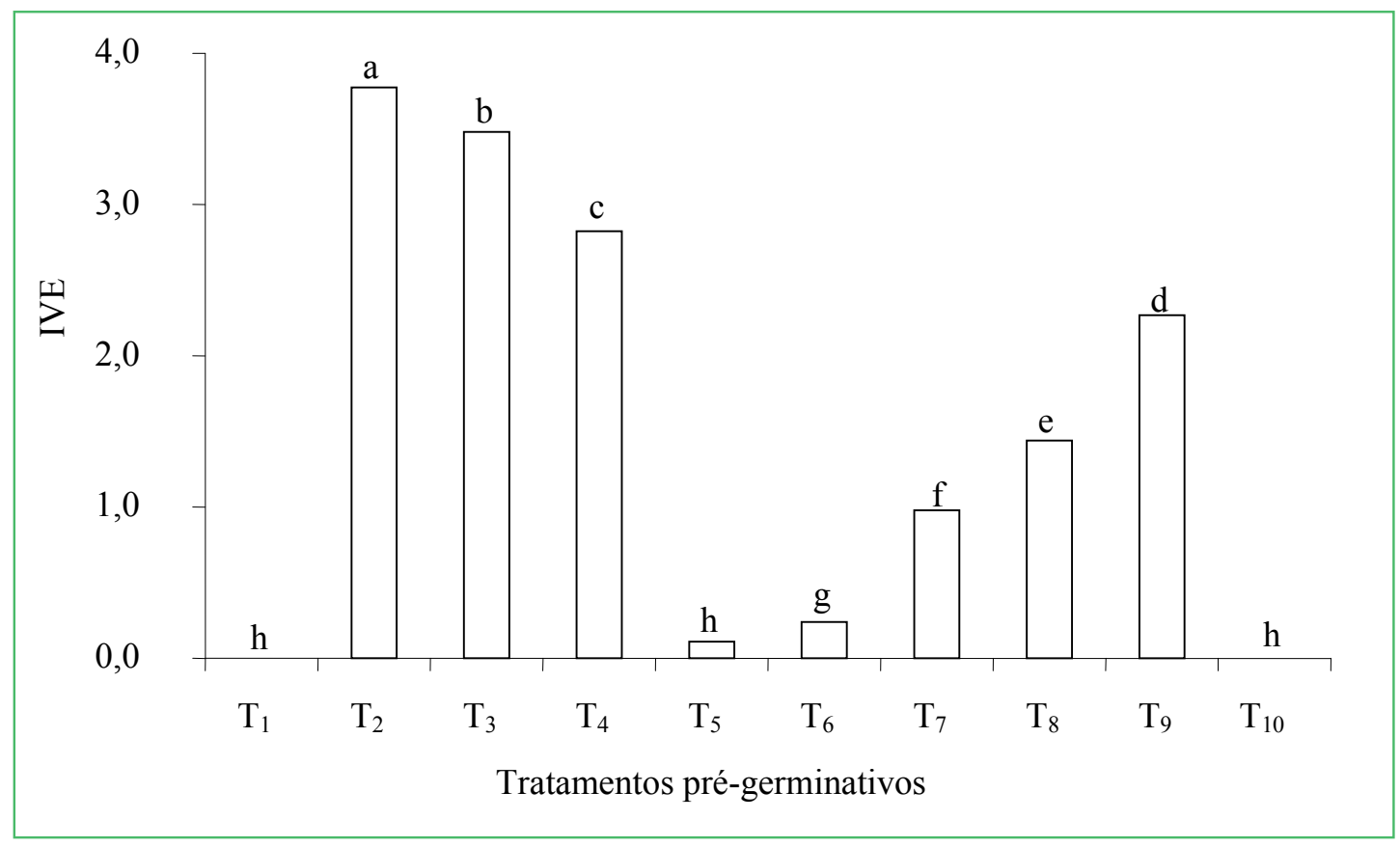


sulfúrico, a imersão por $20 \min \left(\mathrm{T}_{9}\right)$ foi responsável pelo maior IVE $(2,27)$, indicando que este período de exposição promoveu a escarificação completa do tegumento e consequentemente, permitiu a entrada de água em quantidade adequada ao embrião e o aumento da velocidade do processo germinativo (Figura 3).

De modo semelhante, a imersão em água a temperatura ambiente por $24 \mathrm{~h}$ também foi responsável por baixos porcentuais de emergência na primeira contagem de sementes de Cassia excelsa Scharad (JELLER; PEREZ, 1999) e Merremia aegyptia L. (PEREIRA et al., 2007).

Em ambiente natural, a dormência pode ser superada por processos naturais de escarificação, que consistem em qualquer tratamento que resulte na ruptura ou enfraquecimento do tegumento, permitindo a entrada de água e gases e, assim, dando início ao processo germinativo (MAYER; POLJAKOFF-MAYBER, 1989). Comprova-se com os dados que a espécie C. fistula apresenta dormência e para que a mesma possa germinar em seu ambiente natural, sugere-se que a escarificação ocorra naturalmente pelo aquecimento úmido ou seco do solo, por alternância de temperaturas, permitindo, assim, a entrada de água para o interior da semente. A escarificação também pode ocorrer pela ação de ácidos durante a ingestão das sementes por animais dispersores, pela ação dos microrganismos do solo (VAZQUEZYANES; OROZCO-SEGOVIA, 1993) ou ação de possíveis predadores, que perfuram as sementes.

Assim como foi registrado para as sementes de C. fistula, a escarificação com lixa proporcionou os maiores índices de velocidade de emergência de plântulas de Caesalpinia pyramidalis Tul. (ALVES et al., 2007), Senna siamea (DUTRA et al., 2007), Bowdichia virgilioides (ALBUQUERQUE et al., 2007) e de Merremia aegyptia L. (PEREIRA et al., 2007). Já a utilização do ácido sulfúrico concentrado se mostrou eficaz em aumentar a velocidade de germinação em sementes de Bowdichia virgilioides Kunth. por $5 \mathrm{~min}$ (SMIDERLE; SOUZA, 2003); em sementes de Ormosia arborea (Vell.) Harms por 10, 20 e 30 min (LOPES et al., 2004); em sementes de Caesalpinia pyramidalis Tul., por 8 e 10 min (ALVES et al., 2007) e em Senna alata L. por 60 min (BRAGA et al., 2010).

A Figura 4 apresenta os dados de comprimento das plântulas. O comprimento máximo de plântulas $(16,86 \mathrm{~cm})$ foi oriundo de sementes $C$. fistula submetidas

FIGURA 4: Comprimento de plântulas de Cassia fistula L., oriundas de sementes submetidas a tratamentos para superar a dormência. $\mathrm{T}_{1}$ - Testemunha - sementes intactas; $\mathrm{T}_{2}$ - Escarificação mecânica com lixa d'água no 80 na lateral da semente; $\mathrm{T}_{3} \mathrm{e} \mathrm{T}_{4}-$ Escarificação mecânica com lixa d'água $\mathrm{n}-80$, seguida de embebição em água por $12 \mathrm{~h}$ e $24 \mathrm{~h}$, respectivamente; $\mathrm{T}_{5}, \mathrm{~T}_{6}, \mathrm{~T}_{7}, \mathrm{~T}_{8}$ e $\mathrm{T}_{9}$ - Imersão em ácido sulfúrico por $1,5,1015$ e $20 \mathrm{~min}$, respectivamente; $\mathrm{T}_{10}$ - Imersão em água na temperatura de $100^{\circ} \mathrm{C}$ até esfriamento.

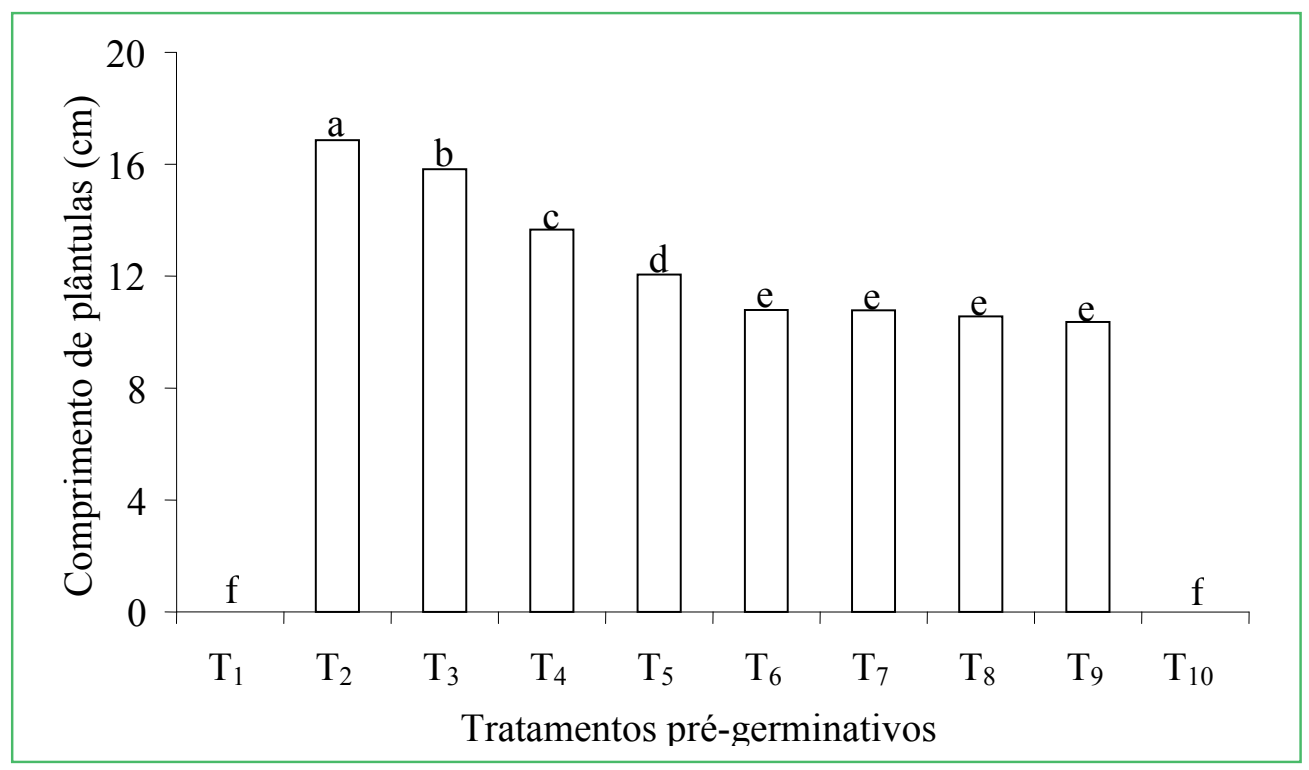


ao tratamento $T_{2}$ (escarificação mecânica com lixa d'água no 80 na região lateral da semente), seguido do tratamento $\mathrm{T}_{3}$ (escarificação mecânica com lixa d'água $\mathrm{n}{ }^{\circ} 80$, seguida de embebição por $12 \mathrm{~h}$ ). O que se verifica naturalmente é que as sementes que germinam mais rapidamente tendem a desenvolver plântulas com maior comprimento, o justamente obtido com a análise dos dados, corroborando com os obtidos no IVE (Figura 3).

A fase entre a embebição e formação de plântulas é crítica na produção de mudas especialmente pelo fato que estas podem encontrar condições adversas para a germinação e desenvolvimento da plântula. Assim, a redução de tempo de germinação e emergência pode resultar em maior sucesso no estabelecimento e na ocupação de uma área, ou mesmo para produção de mudas, sendo, portanto, vantajoso promover uma emergência mais rápida e uniforme das plântulas no campo ou na sementeira.

Além das sementes de C. fistula identifica-se outras sementes que originaram plântulas com maior comprimento quando escarificadas mecanicamente. Em Acacia mearnsii, a escarificação mecânica por 15 segundos foi responsável pelos maiores valores de comprimento da raiz das plântulas (ROVERSI et al., 2002). Sementes de Merremia aegyptia L. submetidas aos tratamentos de escarificação mecânica e imersão em ácido sulfúrico por seis min originaram plântulas com maior comprimento (PEREIRA et al., 2007). A escarificação mecânica com lixa d'água no 80 por 5 min também promoveu maiores comprimentos de plântulas de Apeiba tibourbou Aubl. (GUEDES et al., 2011).

Verificou-se que as sementes imersas em ácido sulfúrico, independente do período de exposição, apresentaram redução do vigor (comprimento de plântulas). É possível que a ruptura do tegumento tenha permitido a infiltração do ácido que ao atingir células essenciais, pode ter havido comprometimento do desenvolvimento das plântulas, embora houvesse um alto porcentual de emergência, como foi registrado no tratamento $T_{9}$ (imersão em ácido por $20 \mathrm{~min}$ ). A escarificação química propicia a degradação do tegumento e o aumento do período de imersão poderá causar ruptura de células essenciais e favorecer injúrias mecânicas e invasão de fungos e como consequência, prejudicar a emergência (ROLSTON, 1978) e o desenvolvimento da plântula como foi observado no presente trabalho.

A aplicação do ácido sulfúrico promoveu a redução do comprimento de plântulas de $C$. fistula. Comportamento similar ao registrado para esta espécie também foram observados na espécie Acacia mangium Willd. em que a utilização de ácido sulfúrico concentrado superou a dormência tegumentar das sementes, mas resultou em crescimento anormal das plântulas (LIMA; GARCIA, 1996). Plântulas de Bowdichia virgilioides H.B.K. oriundas de sementes imersas em ácido sulfúrico concentrado por períodos superiores a 2 min também apresentaram redução do crescimento (SAMPAIO et al., 2001).

Os maiores conteúdos de massa seca das plântulas $(0,0478 \mathrm{~g})$ foram registrados para o tratamento em que as sementes foram escarificadas mecanicamente $\left(\mathrm{T}_{2}\right)$. Sementes de Acacia mearnsii Will. quando foram escarificadas com lixa por 15 min originaram plântulas com maior conteúdo de massa seca (ROVERSI et al., 2002).

Assim como se verificou no comprimento de plântulas, o vigor (massa seca) foi afetado negativamente à medida que aumentou o tempo de imersão das sementes no ácido sulfúrico. Em sementes de Opuntia inamoena Schum a imersão em ácido sulfúrico por 10 min e imersão em água por 3 e 5 min reduziu o conteúdo de massa seca de plântulas (GUEDES et al., 2008) (Figura 5).

É comprovado, portanto, que a superação de dormência de sementes $C$. fistula torna-se importante para garantir que haja produção de mudas e um potencial para propagação desta espécie ainda não domesticada. Fowler e Bianchetti (2000), que, em levantamento de técnicas para a superação de dormência de espécies florestais, apontaram que a utilização de ácido sulfúrico, assim como tratamentos mecânicos de retirada do tegumento, são procedimentos eficazes para espécies pertencentes à família Fabaceae, tais como $C$. fistula. Isto pode ser comprovado com os resultados obtidos para superar a impermeabilidade do tegumento de sementes de $C$. fistula em que se recomenda a escarificação mecânica com lixa d'água $n^{\circ} 80$ na região 
FIGURA 5: Massa seca de plântulas de Cassia fistula L., oriundas de sementes submetidas a tratamentos para superar a dormência. $\mathrm{T}_{1}$ - Testemunha - sementes intactas; $\mathrm{T}_{2}$ - Escarificação mecânica com lixa d'água $\mathrm{n}^{\circ} 80$ na lateral da semente; $\mathrm{T}_{3}$ e $\mathrm{T}_{4}-$ Escarificação mecânica com lixa d'água $\mathrm{n}^{\circ} 80$, seguida de embebição em água por $12 \mathrm{~h}$ e $24 \mathrm{~h}$, respectivamente; $\mathrm{T}_{5}, \mathrm{~T}_{6}, \mathrm{~T}_{7}, \mathrm{~T}_{8}$ e $\mathrm{T}_{9}$ - Imersão em ácido sulfúrico por 1, 5, 1015 e $20 \mathrm{~min}$, respectivamente; $\mathrm{T}_{10}$ - Imersão em água na temperatura de $100^{\circ} \mathrm{C}$ até esfriamento.

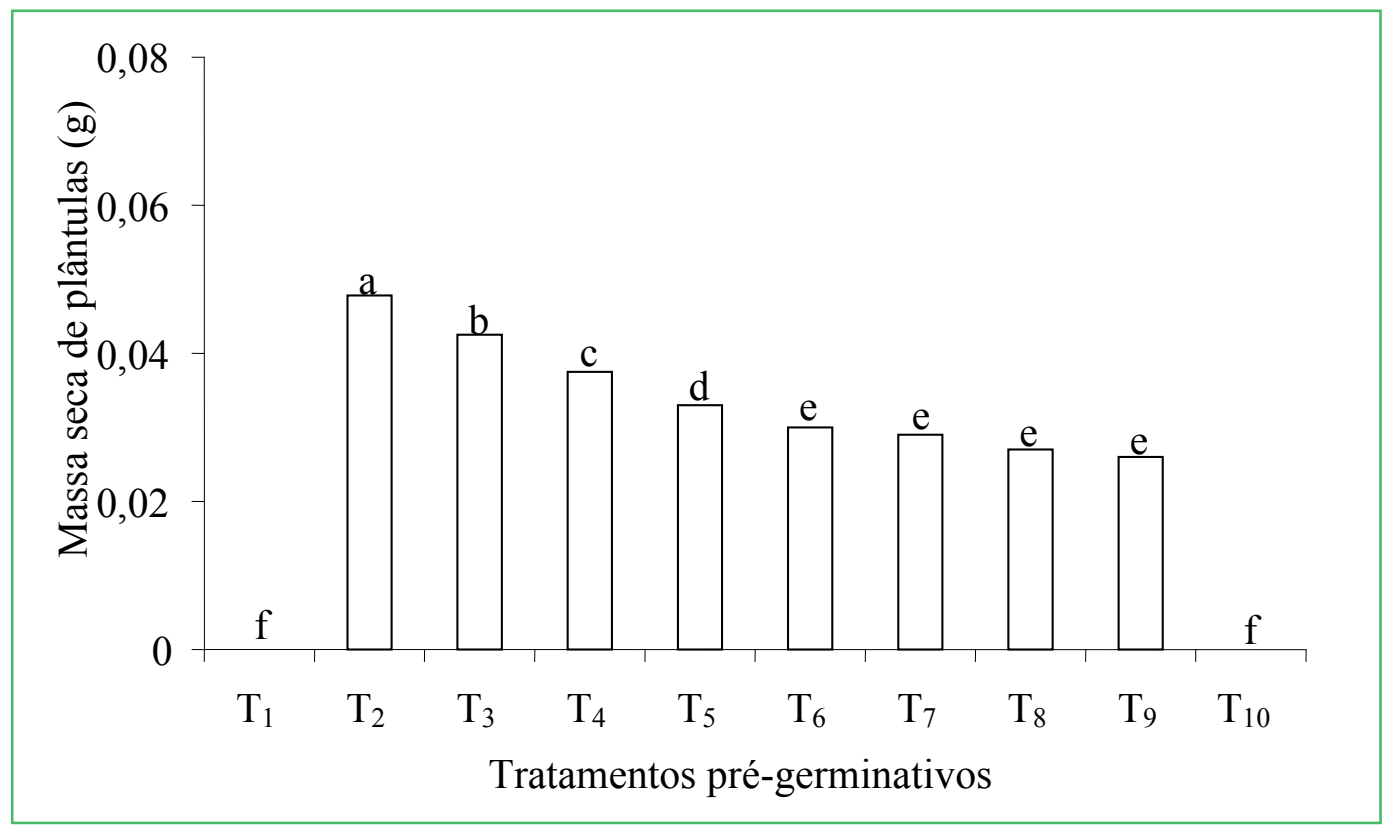

lateral da semente, que resultou em maior emergência e desenvolvimento de plântulas. Além disso, é sugerida como forma alternativa a aplicação de ácido sulfúrico por 20 min, sendo recomendada, entretanto, a ampliação de períodos de exposição ao ácido para verificar a eficácia no acréscimo do porcentual de germinação, o que facilitaria o uso da espécie na produção de mudas.

Em síntese recomenda-se escarificar as sementes de $C$. fistula com lixa d'água $\mathrm{n}^{\circ} 80$ na região lateral da semente e alternativamente imergir em ácido sulfúrico por $20 \mathrm{~min}$.

\section{Referências}

ALBUQUERQUE, K. S.; GUIMARÃES, R. M.; ALMEIDA, F. I.; CLEMENTE, A. C. S. Métodos para a superação da dormência em sementes de sucupira-preta (Bowdichia virgilioides KUNTH.). Ciência e Agrotecnologia, Lavras, v. 31, n. 6, p. 1716-1721, 2007.

ALVES, E. U.; CARDOSO, E. A.; BRUNO, R. L. A.; ALVES, A. U.; ALVES, A. U. GALINDO, E. A.; BRAGA JUNIOR, J. M. Superação da dormência de sementes de Caesalpinia pyramidalis Tul. Revista Árvore, Viçosa, v. 31, n. 3, p. 405-415, 2007.
BASQUEIRA, R.A.; PESSA, H.; SOUZA-LEAL, T.; PEDROSODE-MORAES, C. superação de dormência em Ormosia arborea (Fabaceae: Papilionoideae) pela utilização de dois métodos de escarificação mecânica em diferentes pontos do tegumento. Revista em Agronegócios e Meio Ambiente, Maringá, v.4, n.3, p. 547-561, 2011.

BEWLEY, J. D.; BLACK, J. M. Seeds: Physiology of Development and Germination. 2.ed. New York: Plenum Press. 1994. 445p.

BRAGA, L. F.; SOUSA, M. P.; BRAGA, J. F.; DELACHIAVE, M. E. A. Escarificação ácida, temperatura e luz no processo germinativo de sementes de Senna alata (L.) Roxb. Revista Brasileira de Plantas Medicinais, Piracicaba, v. 12, n. 1, p. 1-7, 2010.

BRANCALION, P. H. S.; MONDO, V. H. V.; NOVEMBRE, A. D. L. C. Escarificação química para a superação da dormência de sementes de saguaraji-vermelho (Colubrina glandulosa perk. - Rhamnaceae). Revista Árvore, Viçosa, v. 35, n. 1, p. 119-124, 2011.

CASTRO, R. D.; BRADFORD, K. J.; HILHOSRT, H. W. M. Embebição e reativação do metabolismo. In: FERREIRA, A. G.; BORGHETI, F. (Ed.). Germinação: do básico ao aplicado. Porto Alegre: Artmed, 2004. p. 149-162.

CORRÊA, M. P. Dicionário de plantas úteis do Brasil e exóticas cultivadas. Vol. 1. Rio de Janeiro: MA/IBDF, 1984. 747 p.

DUTRA, A. S.; MEDEIROS FILHO, S.; TEÓFILO, E. M.; DINIZ, F. O. Germinação de sementes de Senna siamea (Lam.) H.S. Irwin e Barneby - Caesalpinioideae. Revista Brasileira de Sementes, Londrina, v. 29, n. 1, p. 160-164, 2007. 
ESCOBAR, T. A.; PEDROSO, V. M.; BONOW, R. N.; SCHWENGBER, E. B. Superação de dormência e temperaturas para germinação de sementes de Acacia caven (Mol.) Mol. (espinilho). Revista Brasileira de Sementes, Londrina, v. 32, n. 2, p. 124-130, 2010.

FOWLER, A. J. P.; BIANCHETTI, A. Dormência em sementes florestais. Colombo: Embrapa Florestas, 2000. 27 p. (Embrapa Florestas. Documentos, 40)

GUEDES, R. S.; ALVES, E. U.; GONÇALVES, E. P.; VIANA, J. S.; MOURA, M. F.; SANTOS, S. S. Germinação de sementes de Opuntia inamoena schum após tratamentos para superar a dormência. Revista da Farmácia e Biologia, Campina Grande, v. 3, n. 1, on line, 2008.

GUEDES, R. S.; ALVES, E. U.; VIANA, J. S.; GONÇALVES, E. P.; SANTOS, S. R. N.; COSTA, E. G. Tratamentos pré-germinativos e temperaturas para a germinação de sementes de Apeiba tibourbou Aubl. Revista Brasileira de Sementes, Londrina, v. 33, n. 1, p. 131-140, 2011.

HARTMANN, H. T.; KESTER, D. E.; DAVIES JUNIOR, F. T.; GENEVE, R. L. Plant propagation: principles and practices. $6 \mathrm{ed}$. New Jersey: Simom \& Schuster, 1997. 770 p.

JELlER, H.; PEREZ, S. C. J. G. A. Estudo da superação da dormência e da temperatura em sementes de Cassia excelsa Schrad. Revista Brasileira de Sementes, Londrina, v. 21, n. 1, p. 32-40, 1999.

LAGO, J. H. G.; YOUNG, M. C. M.; SARTORELLI, P. Ésteres arílicos de sementes de Cassia fistula (Leguminosae) com atividade antifúngica. In: REUNIÃO ANUAL DA SOCIEDADE BRASILEIRA DE QUÍMICA, 32, 2009, Fortaleza. Anais... Fortaleza: Sociedade Brasileira de Química. 2009. Versão eletrônica.

LIMA, D.; GARCIA, L. C. Avaliação de métodos para o teste de germinação em sementes de Acacia mangium Willd. Revista Brasileira de Sementes, Londrina, v. 18, n. 2, p.180-185, 1996.

LOPES, J. C.; DIAS, P. C.; MACEDO, C. M. P. Tratamentos para acelerar a germinação e reduzir a deterioração das sementes de Ormosia nitida Vog. Revista Árvore, Viçosa, v. 30, n. 2, p. 171177, 2006.

LOPES, J. C.; DIAS, P. C.; MACEDO, C. M. P. Tratamentos para superar a dormência de sementes de Ormosia arborea (Vell.) Harms. Brasil Florestal, São Paulo, n. 80, p. 25-35, 2004.

LUXIMON-RAMMA, A.; BAHORUN, T.; SOOBRATTEE, M. A.; ARUOMA, O. I. Antioxidant activities of phenolic, proanthocyanidin, and flavonoid components in extracts of Cassia fistula. Journal of Agricultural and Food Chemistry, Washington, v. 50, n. 18, p. 5042-5047, 2002.

MAGUIRE, J. D. Speed of germination aid in selection and evaluation for seedling emergence and vigor. Crop Science, Zurich, v. 2, n. 2, p. 176-177, 1962.

MAYER, A. C.; POLJAKOFF-MAYBER, A. The germination of seeds. London: Pergamon Press, 1989. 270 p.

MELO, J. T.; SILVA, J. A.; TORRES, R. A. A.; SILVEIRA, C. E. S.; CALDAS, L. S. Coleta, propagação e desenvolvimento inicial de espécies do cerrado. In: SANO, S. M.; ALMEIDA, S. P. (Ed.). Cerrado: ambiente e flora. Planaltina: EMBRAPA/CPAC, 1998. p. $195-235$.
MOUSSA, H.; MARGOLIS, H. A.; DUBÉ, P. A.; ODONGO, J. Factores affecting the germination of doum palm (Hyphaene thebaica Mart.) seeds from the semi-arid of Nger, West Africa. Forest Ecology and Management, Amsterdam, v. 104, n. 1/3, p. 27-34, 1998.

MURDOCH, A. J.; ELLIS, R. H. Dormancy, viability and longevity. In: FENNER, M. (Ed.). Seeds: the ecology of regeneration in plant communities. 2 ed. Wallingford: CABI Publishing, 2000. p. 183214

PEREIRA, E. W. L.; RIBEIRO, M. C. C.; SOUZA, J. O.; LINHARES, P. C. F.; NUNES, G. H. S. Superação de dormência em sementes de jitirana (Merremia aegyptia L.). Revista Caatinga, Mossoró, v. 20, n. 2, p. 59-62, 2007.

PIÑA-RODRIGUES, F. C. M.; AGUIAR, I. B. Maturação e dispersão de sementes. In: AGUIAR, I. B.; PIÑA-RODRIGUES, F. C. M.; FIGLIOLIA, M. B. (Org.). Sementes florestais tropicais. Brasília: ABRATES, 1993. p. 83-135.

PINEDO, G. J. V.; FERRAZ, I. D. K. Hidrocondicionamento de Parkia pendula [Benth ex Walp]: sementes com dormência física de árvore da Amazônia. Revista Árvore, Viçosa, v. 32, n. 1, p. 3949, 2008.

PIROLI, E. L.; CUSTÓDIO, C. C.; ROCHA, M. R. V.; UDENAL, J. L. Germinação de sementes de canafístula Peltophorum dubium (Spreng.) Taub. tratadas para superação da dormência. Colloquium Agrariae, Presidente Prudente, v. 1, n. 1, p. 13-18, 2005.

POPINIGIS, F. Fisiologia de sementes. Brasília, AGIPLAN, 1977. $289 \mathrm{p}$

RODRIGUES, A. P. D. C.; KOHL, M. C.; PEDRINHO, D. R.; ARIAS, E. R. A.; FAVERO, S. Tratamentos para superar a dormência de sementes de Acacia mangium Willd. Acta Scientiarum Agronomy, Maringá, v. 30, n. 2, p. 279-283, 2008.

RODRIGUES, A.P.D.C. Tratamentos parasuperação da dormência de sementes de Adenanthera pavonina L. Revista Árvore, Viçosa, v. 33, n. 4, p. 617-623, 2009.

ROLSTON, M. P. Water impermeable seed dormancy. The Botanical Review, New York, v. 44, n. 33, p. 365-396, 1978.

ROVERSI, T.; MATTEI, V. L.; SILVEIRA JÚNIOR, P.; FALCK, G. L. Superação da dormência em sementes de acácia negra (Acacia mearnsii Willd.). Revista Brasileira de Agrociência, Fortaleza, v. 8, n. 2, p. 161-163, 2002.

SAMPAIO, L. S. V.; PEIXOTO, C. P.; PEIXOTO, M. F. S. P.; COSTA, J. A.; GARRIDO, M. S.; MENDES, L. N. Ácido sulfúrico na superação da dormência de sementes de sucupira preta (Bowdichia virgilioides Kunth. - Fabaceae). Revista Brasileira de Sementes, Londrina, v. 23, n. 1, p. 184-190, 2001.

SANTOS, A. L. F. Superação de dormência de sementes de espécies florestais empregadas na recuperação de áreas degradadas. 2008. 21 f. Monografia (Curso de Graduação em Engenharia Florestal) - Universidade Federal Rural de Pernambuco, Recife. 2008.

SANTOS, E. Nossas madeiras. Vol. 7. Belo Horizonte: Itatiaia. Coleção Vis Mea in Labore, 1987. 313 p.

SCHMIDT, L. Dormancy and pretreatment. In: OLSEN, K. (Ed.) Guide to handling of tropical and subtropical forest seed. Humlebaek: Danida Forest Seed Centre, 2000. p. 263-303. 
SILVA, A. G.; COSTA, L. G.; GOMES, D. R.; BROCCO, V. F. Testes para quebra de dormência de sementes de Cassia grandis L. e, morfologia de sementes, frutos e plântulas. Enciclopédia Biosfera, Goiânia, v. 8, n. 14, p. 907-912, 2012.

SILVA, A. I. S.; CORTE, V. B.; PEREIRA, M. D.; CUZZUOL, G. R. F.; LEITE, I. T. A. Efeito da temperatura e de tratamentos prégerminativos na germinação de sementes de Adenanthera pavonina L. Semina: Ciências Agrárias, Londrina, v. 30, n. 4, p. 815-824, 2009.

SMIDERLE, O. J.; MOURÃO JUNIOR, M.; SOUSA, R. C. P. Tratamentos pré-germinativos em sementes de acácia. Revista Brasileira de Sementes, Londrina, v. 27, n. 1, p. 78-85, 2005.

SMIDERLE, O. J.; SOUSA, R. C. P. Dormência em sementes de paricarana (Bowdichia virgilioides Kunth - Fabaceae Papilionoideae). Revista Brasileira de Sementes, Londrina, v. 25, n. 1, p. 72-75, 2003.

VASQUEZ-YANES, C.; OROZCO-SEGOVIA, A. Patterns of seed longevity and germination in the tropical rain forest. Annual Review of Ecology and Systematics, Palo Alto, v. 24, n. 1, p. 6987, 1993. 